\title{
Development of an Electrical Power Quality Monitor Based on a PC
}

\author{
Renato Alves ${ }^{1}$, D. Gonçalves ${ }^{1}$, J. G. Pinto ${ }^{1}$, José Batista ${ }^{2}$, João L. Afonso ${ }^{1}$ \\ ${ }^{1}$ DEI, Universidade do Minho, Portugal. \\ ${ }^{2}$ Instituto Politécnico de Bragança, Portugal. \\ e-mail: ralves@dei.uminho.pt, dgoncalves@dei.uminho.pt, gpinto@dei.uminho.pt, jbatista@ipb.pt, jla@dei.uminho.pt
}

\begin{abstract}
This paper describes an Electric Power Quality Monitor developed at the University of Minho. The hardware of the Monitor is constituted by four current sensors based on Rogowski effect, four voltage sensors based on $\mathrm{Hall}$ effect, a signal conditioning board and a computer. The software of the Monitor consists of several applications, and it is based on LabVIEW. The developed applications allow the equipment to function as a digital scope, analyze harmonic content, detect and record disturbances in the voltage (wave shapes, sags, swells, and interruptions), measure energy, power, unbalances, power factor, register and visualize strip charts, register a great number of data in the hard drive and generate reports. This article also depicts an Electrical Power Quality Monitor Integrated into Active Power Filters developed at the University of Minho.
\end{abstract}

\section{INTRODUCTION}

With the great development of electronic equipment in recent decades, there has been a proliferation of non linear loads connected to the power grid, causing a growing deterioration of the Electric Power Quality. Before the big evolution of the electronic equipment, the problems of power quality were basically interruptions in the supply. Currently, many others factors influence the Electric Power Quality, since more and more loads are sensitive and non linear. Of the main problems of power quality, the following ones are distinguished: sags, swells, transients, harmonics, highfrequency noise, notches, flicker, unbalances and frequency variations. Currently, the Electric Power Quality is an important factor to take into account in electrical installations. A problem of power quality can cause large damages, for example in an industry it can cause an interruption of a process and this can mean the stopping of the company during some hours. Thus, it is important to carry out monitoring of Electric Power Quality, to detect and diagnose problems of quality of energy and trace profiles of energy consumption. The monitoring may also serve to find out if the problem has origin in the consumer or in the supplier of electricity, thus, allowing to verify if the parameters of quality of the energy stipulated are being fulfilled. With the environment issues and scarcity of the natural recourses, both in public opinion but also at political level, energy consumption has become a global concern. It is therefore an important issue how to use the energy in a rational way. It is important that consumers know the profile of their electrical installations, to take measures that can reduce losses and optimize the energy consumption [1].

In Europe, the CENELEC (European Committee for Electrotechnical Standardization) created a norm, called EN 50160. This norm establishes, in the point of delivery to the customer (PCC - Point of Common Coupling), the parameters of quality of the voltage supplied by a public distribution system. This norm already was adopted by some European countries. Other international organizations, as International Electrotechnical Commission (IEC) and the Institute of Electrical and Electronics Engineers (IEEE) also elaborated norms aiming to limit the harmonic contents in the voltages of the electrical systems, namely norm IEEE-519 and norm IEC 61000

\section{HARDWARE DESCRIPTION}

The Power Quality Monitor is an equipment that has been developed in the Laboratory of Power Electronic of the Department of Industrial Electronics of the University of Minho. This equipment has the ability to analyze the quality of energy of determinate electrical system and also to record and classify some of the problems detected. The Monitor developed is based in a PC (Personal Computer), thus seeking to become a low cost equipment compared with other of the same type on the market [2][3]. Two versions of this equipment have been developed. One version which we call Independent Monitor, is the traditional that are used in the measurements of the electric boards, the other version is destined to be integrated in the Shunt Active Power Filters developed in the University of Minho that we call Integrated Monitor. The Integrated Monitor was developed based on the Independent Monitor.

In terms of hardware, the Independent Monitor consists of four voltage sensors, four current sensors, one signal conditioning board, one data acquisition card and one computer. The Integrated Monitor takes the voltage and current measurements of the Shunt Active Power Filter and thus only needs to add three current sensors to measure the source currents. In Fig. 1 it is presented a block diagram where it is possible to view the components of the Monitor and their internal links. In Fig. 2 it is presented the block diagram of the connection of the Integrated Monitor to the Shunt Active Filter. 


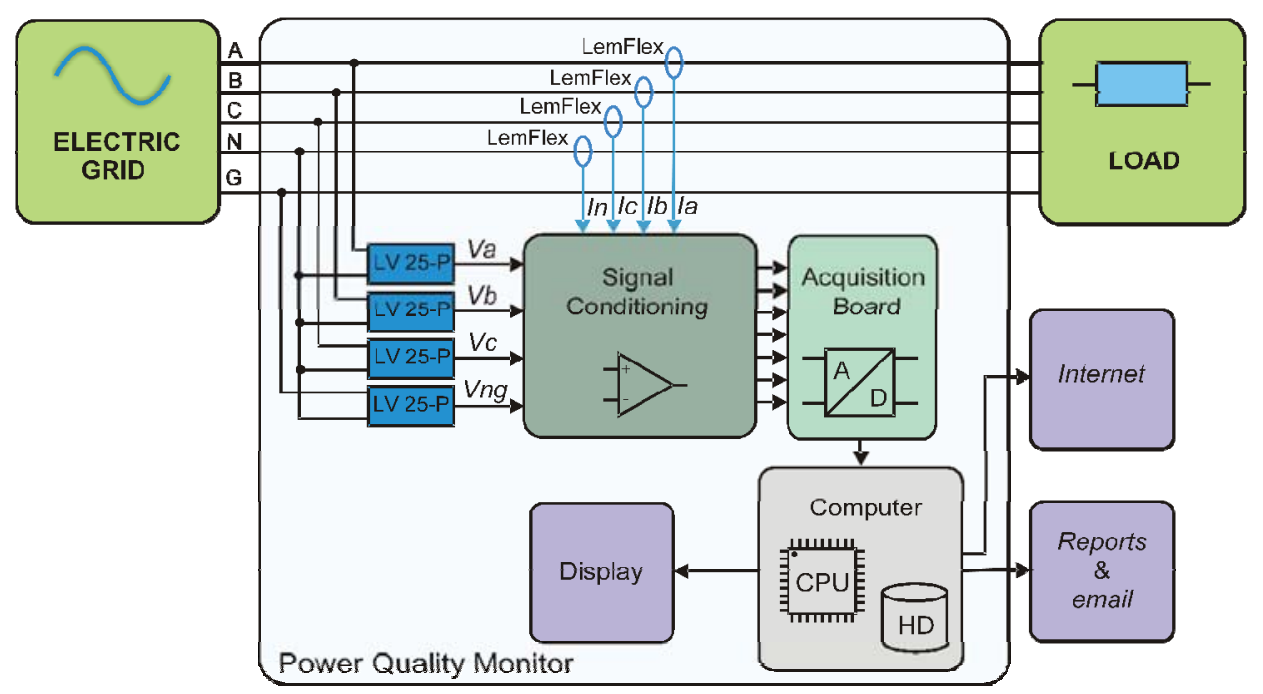

Fig. 1. Block diagram of the Independent Monitor.

The voltage sensors used in the Monitor are from the manufacturer LEM (model LV 25-P) whose appearance can be seen in Fig. 3 a). These sensors can measure DC and AC voltages up to $500 \mathrm{~V}$. They can measure $\mathrm{AC}$ voltages with frequencies until $50 \mathrm{kHz}$. The functioning is based in the Hall effect with closed loop control. Furthermore, they provide the electrical insulation between the high voltage side (primary) and the side of measure (secondary) [1].

The current sensors used in the Monitor are from the manufacturer LEM (model LemFlex RR3020), shows in Fig. $3 \mathrm{~b})$. These sensors only measure AC currents with frequencies between $10 \mathrm{~Hz}$ and $20 \mathrm{kHz}$. The three scales of the sensor allow the measurement of currents of up to $3000 \mathrm{~A}$ RMS. Their functioning is based in Rogowski effect. It's not necessary to interrupt the circuit to install the sensor and because they are flexible it more facilitates their installation in tight places [1]. The pictures of Fig. 3 are in different scales.

The signal conditioning board of the Monitor (

Fig. 4) is responsible to adapt, in voltage levels, the signals provided of the sensors, so that they can be properly read from the data acquisition card. This board also is responsible to feed the voltage and current sensors. This board has two possibilities of configuration: one where the voltage signals are measured in relation to the neutral, and another one where it is possible to measure the difference of voltage between two points (for example between two phases). To modify the configuration of the board it is necessary to change the position of the jumpers of the board.

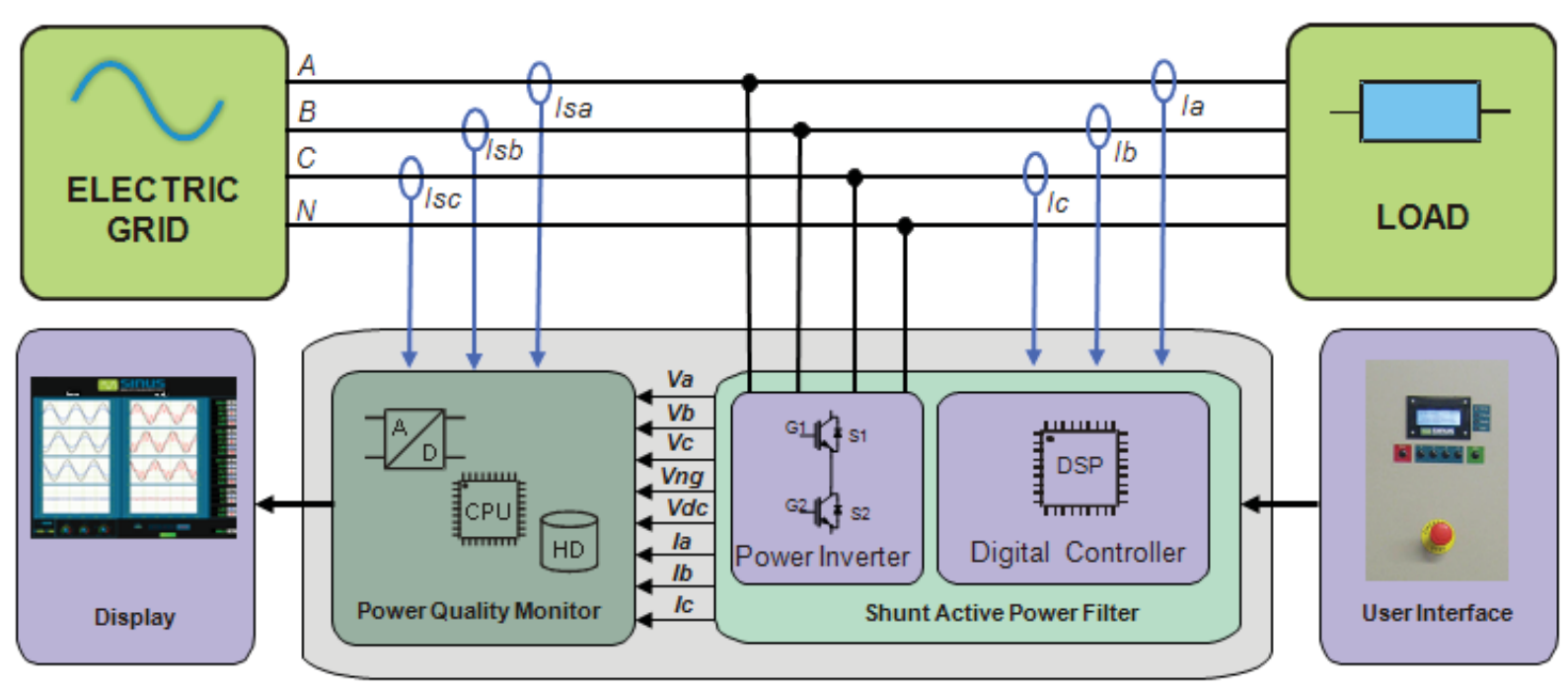

Fig. 2. Block diagram of the Monitor Integrated in the Shunt Active Power Filter. 


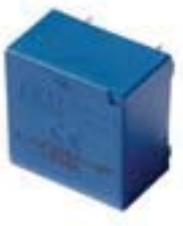

a)

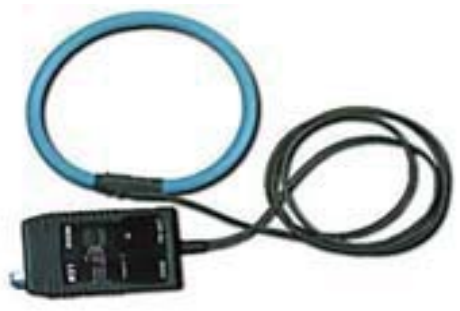

b)
Fig. 3- Sensors of the Monitor: (a) voltage sensor LV 25-P (b) current sensor LemFlex RR2030.

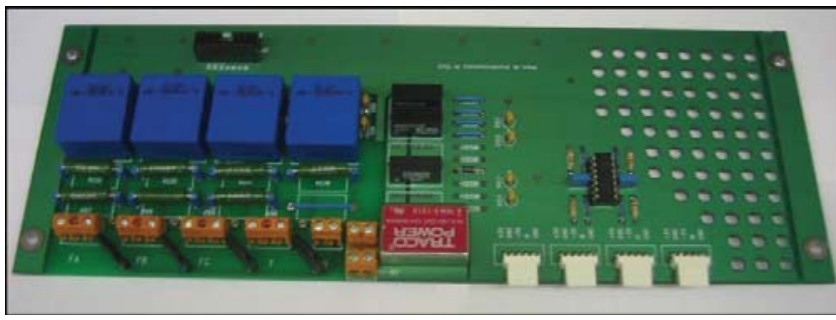

Fig. 4- Signal conditioning board.

The data acquisition card utilized ( ational Instruments, model I PCI- 220) has 1 analog inputs ( in differential mode) and 24 digital inputs outputs. In the Independent Monitor there are used analog inputs and in the Integrated Monitor there are used 11 analog inputs.

The computer is constituted by a motherboard (EPIA mini PC, model MII 12000), equipped with a 1,2 Hz processor and a memory RAM of $1 \mathrm{~B}$. To save the software and the data collected in the monitoring it is use a hard disk of $0 \quad B$ that gives to the Monitor a storage capacity very superior to the monitors existing in the market [1]. In Fig. 5 it is shown the Independent Monitor in the transporting case. The Integrated Monitor is shown in Fig.

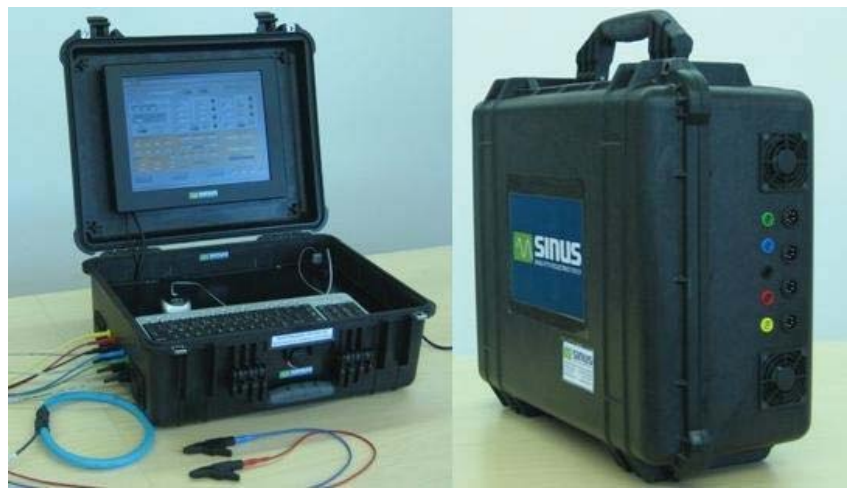

Fig. 5- Independent Monitor in the transport case.

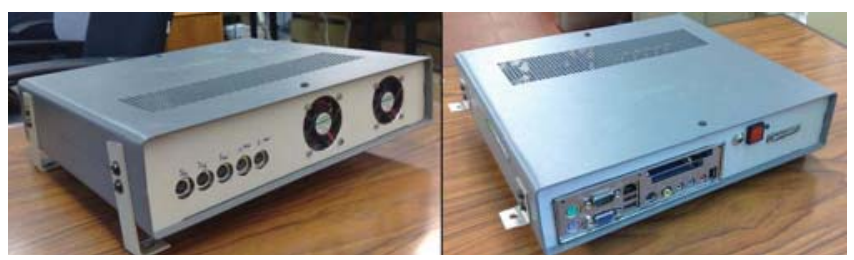

Fig. - Integrated Monitor.

\section{S FT ARE DESCRIPTI}

The software of the Electric Power uality Monitor is constituted by several applications and is based in LabView. The developed applications allow the equipment functioning like digital oscilloscope, analyze harmonic contents, detect and record voltage distortions (sags, swells, interruptions, wave shapes), measure energy, power, voltage and current unbalance, power factor, record and watch strip charts and generate reports[1] [4].

\section{A. Application "Scope and THD"}

This application works as a digital oscilloscope with its main core functions: time base, vertical scale, trigger, frequency, true RMS values, DC values and peak to peak values. Another functionality of this application is the calculation of the Total Harmonic Distortion, including harmonic components until 5 order of the signal [1]. The appearance of the Scope and THD application in the Integrated Monitor can be seen in Fig. and the Fig. shows the appearance of this application for the Independent Monitor.

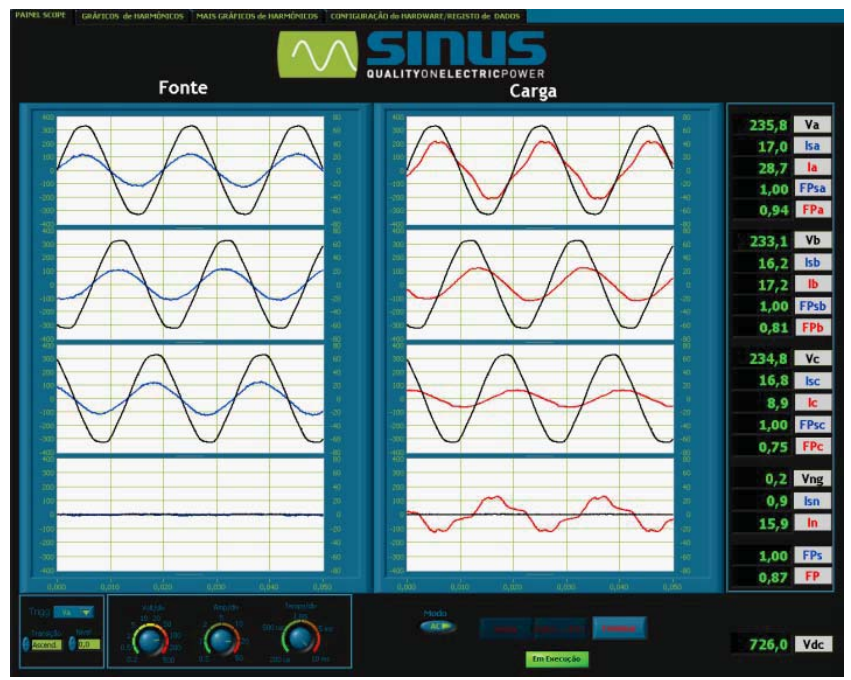

Fig. - Interface of the application Scope e THD of the Integrated Monitor

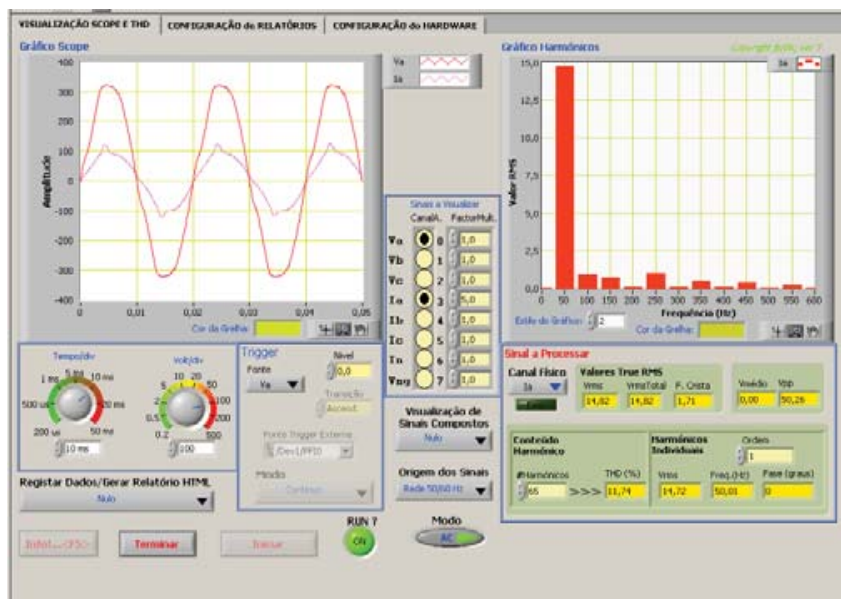

Fig. - Interface of the application Scope and THD of the Independent 


$$
\text { Application " ent o e alit ", }
$$

The application Events $\mathrm{P}$ acquires continuously the voltage and current signals and calculates the following values: True RMS values, THD, unbalances, power factor, power (apparent, active and reactive) and energy (apparent, active and reactive) [1] [2] [5]. These values calculated are saved in files on the hard disk of the Monitor. This application also allows detecting deformations in the form of a voltage wave and if it verifies an anomaly it is saved: the wave form of 12 cycles, cycles before the anomaly and after the anomaly, and also are saved the date and the hour of the occurrence. Furthermore, the equipment is capable of detecting voltage sags and voltage swells. hen these anomalies are detected, it is saved the RMS value of the voltage in the phase where the failure occurred, and also is saved the date and the time of the occurrence. Another functionality available in this application is the possibility to save the waveform of the signals in rate programmable by the user.

The periods of monitoring can be programmed from 1 minute to 30 days. At the end of the sessions, the system sends automatically emails to multiple recipients with information about the end of the monitoring and if events of power quality have occurred. Fig. shows the interface of the application Events P of the Independent Monitor.

\section{Application " epo $t$ "}

The application Reports allows the visualization on the form of tables and graphs the information acquired by the application Events P, allowing also automatically the generation of reports in HTML or ord format. This application is an important aid in the analysis of data recorded during the monitoring, which otherwise, would be much more difficult and more prone to errors of analysis [1] [ ]. Fig. 10 shows the interface of the application Reports of the Independent Monitor.

\section{Application " la ical al e"}

This application calculates various parameters used on the analysis of an electrical system: True RMS values, phase angles, phase impedances, voltage and current unbalance, total and displacement power factor, power (active, reactive, harmonic and apparent), active energy $(\mathrm{k} h)$ and reactive energy (kVArh). In addition to the numerical values, the same information can also be plotted. A feature of this application is the possibility of working in two different modes: Simulation and Acquisition. In the mode Acquisition all the calculations are based on the signals measured by the sensors of the Monitor while in the mode Simulation all the values of the system are calculated on the basis of signals generated by LabView. These signals generated by LabView can be configured by the user in the following parameters: amplitude, frequency and phase, being able to be introduced harmonic components intended for each signal [1] [4] [ ].

\section{Application " $p$ T eo ",}

In this application there are calculated and presented the resultant values of the calculations of the $p$-q theory (Theory of the instantaneous power), being able to be useful in the

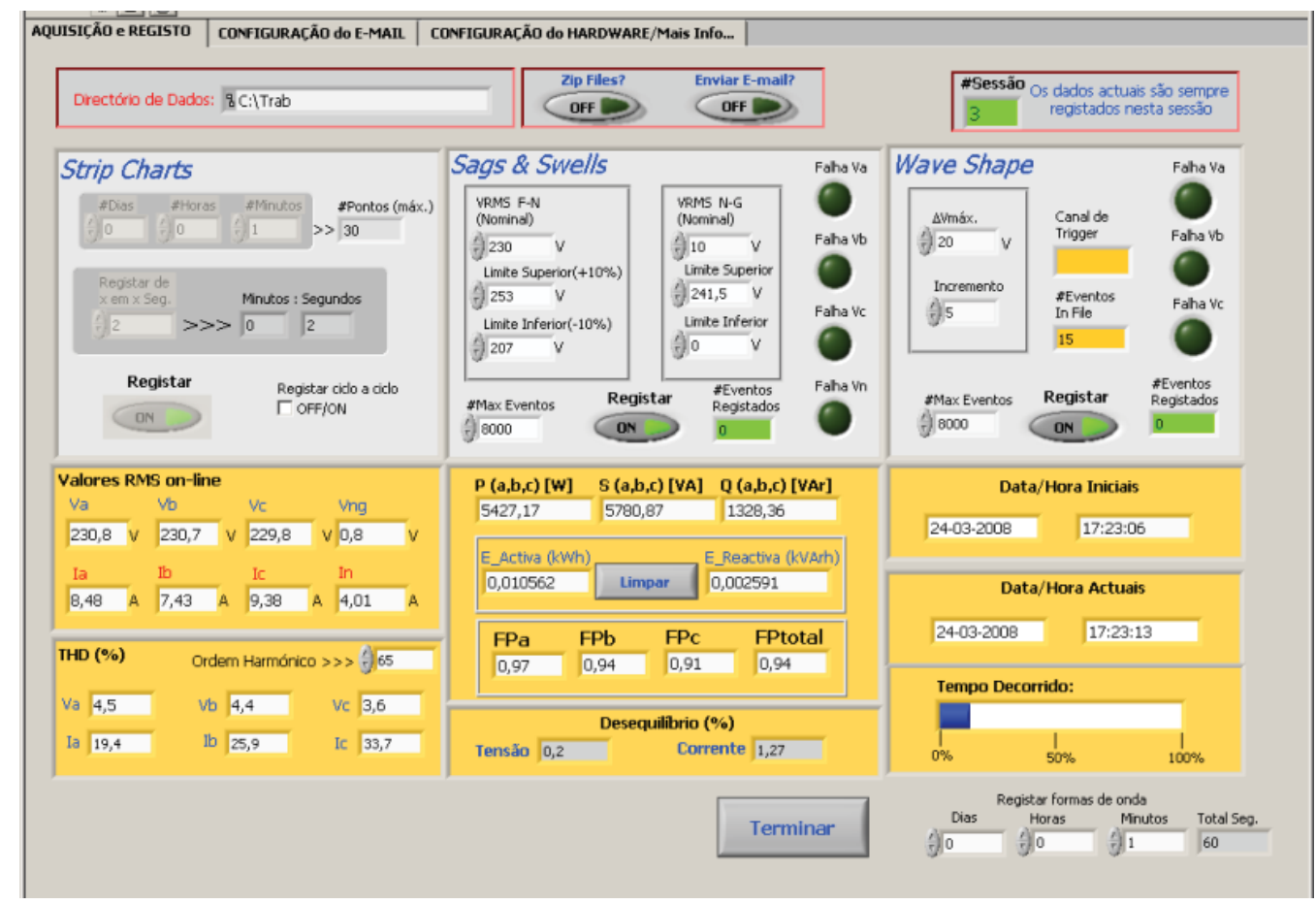

Fig. - Interface of the application Events P of the Independent Monitor. 


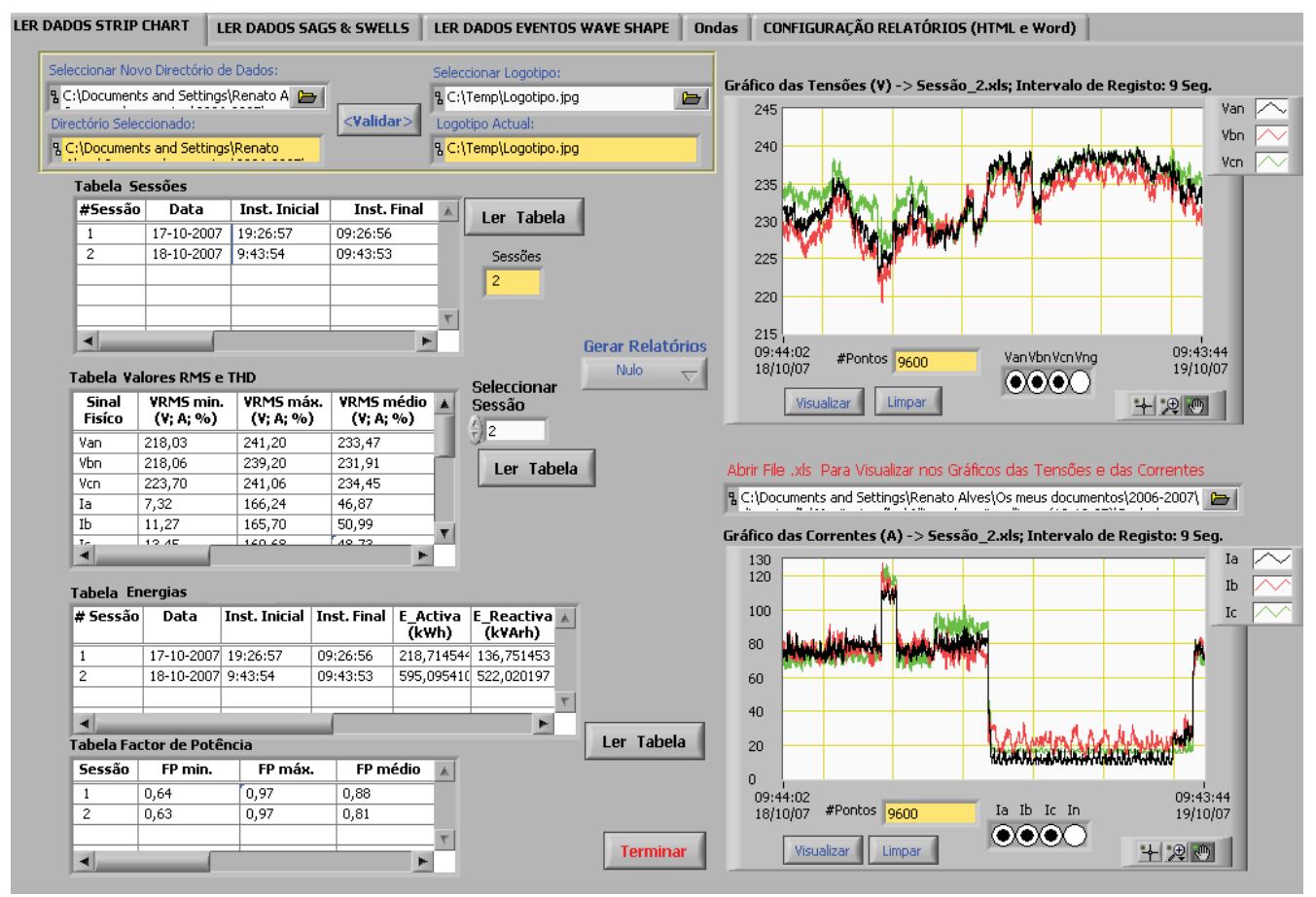

Fig. 10- Interface of the application Reports

analysis of three-phase systems with electrical power problems. This application can also calculate the values of currents and instantaneous power that the source would have to supply if a shunt active power filter was used to compensate for harmonics, reactive power and zero sequence current. The software computes all the quantities which are important to the control of the active filter, and allows the visualization of all relevant signals: voltages, currents and power components, at load, source and active filter. There can be seen up to 34 signals in simultaneous, be divided in two graphs [3][ ][ ]. This application has two distinct modes of functioning: mode Acquisition and mode Simulation functioning as in the case of the application Classical Values. In the mode Simulation it can be configured the same parameters of the signals related in the application Classical Values .

$$
\text { IV. C CL SI S }
$$

This platform is a good solution to implement a power quality monitor because it has a reduced cost and still provides a good performance and reliable results. The use of a PC allows a great versatility of the system and it makes possible to use the Internet and its potential tools.. Another vantage in the use of a PC is the great flexibility that this allows.

The LabVIE is a platform with good resources for the acquisition of signals and data processing. It also provides a very friendly interface with the user.

This paper will be reviewed and enlarged in one more page for the final version.

\section{AC LED ME T}

This work supported by FCT (project funding P CTI ESE411 02001 and P CTI ESE 4242 2002). The authors are grateful to PRIME for funding the Project SI S.

\section{REFERE CES}

[1] Renato Alves Sistema de Monitoriza o de Consumos Energ ticos e da ualidade da Energia El ctrica Tese de Mestrado Integrado niversidade do Minho 200 .

[2] . Batista, . S. Martins, . L. Afonso, LabVIE Monitoriza a ualidade da Energia El ctrica Sistema de Monitoriza o da ualidade da Energia El ctrica Baseado em PC ational Instruments Portugal online https: repositorium.sdum.uminho.pt bitstream $122 \begin{array}{lllll}2 & 5 & 1 & \text { I- }\end{array}$ 05.pdf

[3] . Batista, . S. Martins, . L. Afonso, Low-Cost Power uality Monitor Based on a PC , ISIE'2003 - IEEE International Symposium on Industrial Electronics, R. ., Brasil, un 2003 https: repositorium.sdum.u minho.pt bitstream $1221 \quad 1$ CLEEE B.pdf

[4] os Batista Sistema de Monitoriza o da ualidade da Energia El ctrica Baseada em PC Tese de Mestrado niversidade do Minho 2004.

[5] IEEE, Definitions for the Measurement of Electric Power uantities nder Sinusoidal, onsinusoidal, Balanced, or nbalanced Conditions , IEEE Trial- se Standard, IEEE Std $145-2000,2000$

[ ] o o L. Afonso, Renato Alves, os Batista, Domingos on alves, abriel Pinto e Carlos Couto, Sistema de Monitoriza o de Energia El ctrica , CLME'200 Engenharia e Inova o para o Desenvolvimento, Maputo, Mo ambique, 2-4 Setembro 200.

[ ] . Batista, . S. Martins, . L. Afonso, Sistema de Monitoriza o da ualidade da Energia El ctrica Baseado em PC Congresso LusoEspanhol de Engenharia Electrot cnica Vilamoura, Algarve, Portugal 35 ulho de 2003 https: repositorium.sdum.uminho.pt bitstream 1221 1 CLEEE B.pdf

[ ] . Batista, . S. Martins, . L. Afonso, Low-Cost Digital System for Power uality Monitoring, ICREP '03 International Conference on Renewable Energies and Power uality, Vigo, Spain, April 2003. https: repositorium.sdum.uminho.pt bitstream 1221 1 1 ICREP 03 B.pdf 